This item was submitted to Loughborough's Research Repository by the author.

Items in Figshare are protected by copyright, with all rights reserved, unless otherwise indicated.

\title{
Is there an optimum speed for economical running?
}

PLEASE CITE THE PUBLISHED VERSION

http://dx.doi.org/10.1123/ijspp.2017-0015

\section{PUBLISHER}

(c) Human Kinetics Publishing as accepted for publication

\section{VERSION}

AM (Accepted Manuscript)

\section{PUBLISHER STATEMENT}

This work is made available according to the conditions of the Creative Commons Attribution-NonCommercialNoDerivatives 4.0 International (CC BY-NC-ND 4.0) licence. Full details of this licence are available at: https://creativecommons.org/licenses/by-nc-nd/4.0/

\section{LICENCE}

CC BY-NC-ND 4.0

\section{REPOSITORY RECORD}

Black, Matt I., Joe C. Handsaker, Samuel J. Allen, Stephanie E. Forrester, and Jonathan P. Folland. 2019. "Is There an Optimum Speed for Economical Running?". figshare. https://hdl.handle.net/2134/25084. 


\section{Is there an optimum speed for economical running?}

2 Original Investigation

3

4 Matthew I. Black ${ }^{1}$, Joseph C. Handsaker ${ }^{1,2}$, Sam J. Allen ${ }^{1}$, Stephanie E. Forrester ${ }^{3}$, and 5 Jonathan P. Folland ${ }^{1}$

6

$7 \quad{ }^{1}$ School of Sport, Exercise and Health Sciences, Loughborough University, Leicestershire, 8 LE11 3TU, England, UK.

$9 \quad{ }^{2}$ MAS Innovation, Colombo, Sri Lanka

$10{ }^{3}$ Wolfson School of Mechanical, Electrical and Manufacturing Engineering, Loughborough

11 University, Leicestershire, LE11 3TU, England, UK.

12

13 Address for Correspondence:

14 Matthew I. Black

15 School of Sport, Exercise and Health Sciences, Loughborough University, Leicestershire, 16 LE11 3TU, United Kingdom.

17 Tel: +44 (0)1509 226440

18 E-mail: M.I.Black@lboro.ac.uk

19

20 Running Title: Is there an optimum speed for economical running?

21 Abstract word count: 235

22 Text-only word count: 3854

23 Number of figures and tables: 3 Figures, 1 Table

25 Disclosure of funding: This work was financially supported by MAS Holdings, Sri Lanka 


\section{Abstract}

27 The influence of running speed and sex on running economy is unclear and may have been confounded by measurements of oxygen cost that do not account for known differences in substrate metabolism, across a limited range of speeds, and differences in performance standard. Therefore, this study assessed the energy cost of running over a wide-range of

31 speeds in high-level and recreational runners to investigate the effect of speed (considered in 32 absolute and relative terms) and sex (males vs. females of equivalent performance standard) on running economy. 92 healthy runners (high-level males, $n=14$; high-level females, $n=10$; recreational males, $n=35$; recreational females, $n=33$ ) completed a discontinuous incremental treadmill test for the determination of the energy cost $\left(\mathrm{kcal}^{\mathrm{k}} \mathrm{kg}^{-1} \cdot \mathrm{km}^{-1}\right)$ of submaximal running, speed at lactate turnpoint (sLTP) and the maximal rate of oxygen uptake ( $\mathrm{VO}_{2} \mathrm{max}$ ). There were no sex-specific differences in the energy cost of running for the recreational or highlevel runners when compared at absolute or relative running speeds $(P>0.05)$. The absolute and relative speed-energy cost relationships for the high-level runners demonstrated a curvilinear inverted "u-shape” with a nadir reflecting the most economical speed at $13 \mathrm{~km} . \mathrm{h}^{-1}$ or $70 \%$ sLTP. The high-level runners were more economical than the recreational runners at all absolute and relative running speeds $(P<0.05)$. These findings demonstrate that there is an optimal speed for economical running; there is no sex-specific difference; and, high-level endurance runners exhibit a better running economy than recreational endurance runners. standard 
50 Distance running performance is dependent on the speed that can be sustained for the 51 duration of an event. This speed is determined by the interaction of several physiological 52 factors ${ }^{1}$ which include: the maximal rate of oxygen uptake $\left(\dot{\mathrm{VO}}_{2} \mathrm{max}\right)$; the anaerobic capacity; 53 the fractional utilisation of $\mathrm{V}_{2}$ max; and the conversion of this energy into forward 54 movement, known as running economy. The importance of running economy as a 55 physiological determinant of distance running performance is well documented ${ }^{1,2}$ and is emphasised by its ability to discriminate between performance capabilities in athletes with a

57 similar $\mathrm{V}_{2} \max ^{3}$ Furthermore, distance running events appear to be dominated by highly 58 economical athletes. ${ }^{4}$ However, despite its importance for distance running performance ${ }^{1,2}$, 59 the influence of sex and running speed on running economy remains unclear, and may be 60 confounded by differences in the performance standards of runners.

61 The relationship between speed and running economy is highly equivocal ${ }^{5}$ with reports that running is more ${ }^{6-7}$ and less ${ }^{9}$ energetically expensive as a function of speed. These conflicting 63 findings may be in part due to the relatively small range of speeds (e.g., $\left.\leq 4 \mathrm{~km} \cdot \mathrm{h}^{-1}\right)^{6-8}$ and 64 differing absolute speeds in these studies, which may have limited their ability to describe the full speed-running economy relationship. In contrast, some small reports $(n=9)$ that examined a larger range of speeds observed a curvilinear "u-shaped" relationship between running 67 economy and speed. ${ }^{10,11}$ Further research is therefore necessary to investigate the relationship 68 between running economy and speed in a large sample of runners across a large range of 69 speeds.

71 Evidence for a sex-dependent difference in running economy is also unclear ${ }^{5}$ with reports 72 demonstrating that males ${ }^{12,13}$ and females ${ }^{14,15}$ are the more economical sex, or that there is no 73 difference. ${ }^{7,16}$ Notably, these studies involved a small sample $(n \leq 30)^{7,14,15}$ or were limited to 74 comparisons across absolute speeds. ${ }^{12-14,16}$ Differences in performance standard could explain 
some of the confusion with regard to the influence of sex and speed on running economy.

Performance standard has not been accounted for in the majority of the previous studies of

77 sex and speed even though it has been consistently demonstrated that higher standard runners are more economical. ${ }^{17,18}$ It is therefore important to establish the effect of sex on running

79 80

81

82 economy at the same absolute and relative speeds for runners of equivalent performance standard (e.g. high level and/or recreational).

The majority of the literature concerning running economy, quantified running economy as the oxygen cost to maintain a given speed and/or to cover a given distance based on the assumption that $\dot{\mathrm{VO}}_{2}$ provides an index of the underlying energetic demands. ${ }^{6}$ However, the energy equival ent for a given $\dot{\mathrm{VO}}_{2}$ can vary according to the substrate metabolised, ${ }^{19}$ which has been shown to be dependent on sex, ${ }^{20}$ intensity/speed, ${ }^{21}$ and can be altered with training ${ }^{20}$ and thus is likely to differ according to performance standard. Therefore, the previous comparisons of running speed, sex and performance standard that used the oxygen cost of running as the measure of running economy may have been confounded by differences in substrate metabolism. The assessment of the underlying energy cost accounts for these differences in substrate metabolism and provides a more valid index for the assessment of running economy. ${ }^{6,8}$

Due to the methodological limitations of previous investigations a more comprehensive study that investigates the influence of speed and sex on the energy cost of running across a wide-range of speeds (absolute and relative intensities), and controls for performance standard, is clearly warranted. The purpose of the present study, therefore, was to assess the effect of speed and sex on running economy in a large sample of runners. We hypothesised that: 1) the energy cost of running would increase as a function of running speed; 2) there 
100 would be no sex-specific difference in the energy cost of running at the same absolute or

101 relative speeds (\% speed at lactate turnpoint, \% sLTP) for runners of equivalent performance

102 standard; and, 3) that high-level endurance runners would have a lower energy cost for

103 running at all absolute and relative running speeds compared to recreational runners.

104

\section{METHODS}

106 Participants

107 Ninety-two healthy endurance runners (Table 1) volunteered and gave written informed 108 consent to participate in this study, which had been approved by the Loughborough 109 University Ethical Advisory Committee. All participants were regular runners ( $\geq 2 \mathrm{x}$ per week) 110 who considered running to be their primary sport or physical activity and had a $111 \mathrm{BMI}<24 \mathrm{~kg} \cdot \mathrm{m}^{-2}$. Participants were free from moderate/serious musculoskeletal injury and 112 any minor musculoskeletal injury in the 3 months, and 1 month prior to testing, respectively. 113 Runners were recruited (Table 1) to provide male and female groups of both high-level and 114 recreational runners according to their best running performance in the previous 12 months 115 for distances between $1500 \mathrm{~m}$ and the marathon in UK Athletics sanctioned track and road 116 races. All times were converted to an equivalent 10-km road time using IAAF points scores, ${ }^{23}$ 117 and are presented as a percentage of the 10-km road World Record time (Male, 26 min $44 \mathrm{~s}$; 118 Female, 30 min 21 s). The 24 high-level runners (males, $n=14$; females, $n=10$ ) were within $119115 \%$ of the $10-\mathrm{km}$ World Record Time (<31 min for males; <35 min for females), and the 12068 recreational runners (males, $n=35$; females, $n=33$ ) had achieved between $133-202 \%$ of the 121 10-km World Record Time (35-54 min for males; 40-61 min for females; Table 1).

\section{Experimental Overview}


124 Participants visited the laboratory on two occasions separated by 2-14 days, to perform a 125 treadmill familiarisation and experimental session. Participants were instructed to report to

126 the laboratory in a well-hydrated, rested state, having completed no strenuous exercise within

127 the previous $36 \mathrm{~h}$, after their habitual nutrition and having abstained from alcohol and 128 caffeine for the preceding $24 \mathrm{~h}$, and $6 \mathrm{~h}$ respectively. The experimental visit comprised a 129 submaximal treadmill running test, immediately followed by a maximal treadmill running test. 130 All experimental visits were conducted in the morning (0730-1200), and laboratory 131 conditions were similar for all participants (temperature, $18-20^{\circ} \mathrm{C}$; relative humidity, 45 132 55\%). During both visits, all participants were required to wear the same neutral racing flat 133 shoes (New Balance ${ }^{\circledR}$ RC 1400 v2).

134

\section{Familiarisation}

136 The familiarisation started with the subject 'straddling' the motorised treadmill belt (HP 137 Cosmos, Venus T200, Nussdorf-Traunstein, Germany), such that the treadmill belt could 138 revolve without requiring the participant to run. The participants then practiced lowering 139 themselves onto, and lifting themselves clear of the moving treadmill belt a minimum of 140 three times at each speed, increasing in $1 \mathrm{~km} \cdot \mathrm{h}^{-1}$ increments from $7 \mathrm{~km} \cdot \mathrm{h}^{-1}$ until the 141 participant indicated that they could not continue. Following a period of rest ( $5 \mathrm{~min})$, the 142 subject was fitted in a low-dead space mask and breathed through an impeller turbine 143 assembly (Jaeger Triple V, Jaeger GmbH, Hoechberg, Germany), and repeated the treadmill 144 familiarisation. Following the familiarisation session, the subjects were capable of safely 145 lowering themselves onto the moving treadmill belt and running freely in approximately 3-s.

\section{Experimental visit}

148 Submaximal and maximal running assessment 
149 Participants performed a discontinuous submaximal incremental test for the determination of 150 the energy cost of running, sLTP and $\dot{\mathrm{V}} \mathrm{O}_{2} \max$. The test started at $7 \mathrm{~km} \cdot \mathrm{h}^{-1}$ for females, and

$1518 \mathrm{~km} \cdot \mathrm{h}^{-1}$ for males and consisted of 4 min stages of running at each speed, in increments of $1521 \mathrm{~km} \cdot \mathrm{h}^{-1}$, interspersed by 30-s rest periods during which the subject straddled the moving 153 treadmill belt for fingertip capillary blood sampling. Increments were continued until blood 154 lactate (BLa) had risen $>2 \mathrm{mmol} \cdot \mathrm{L}^{-1}$ from the previous stage (or exceeded $4 \mathrm{mmol} \cdot \mathrm{L}^{-1}$ ), at 155 which point, the participant started the maximal running assessment, and the treadmill speed 156 was increased by $1 \mathrm{~km} \cdot \mathrm{h}^{-1}$ every 2 min until volitional exhaustion. Pulmonary gas exchange 157 was recorded throughout.

159 Measurements

160 Anthropometry

161 During the experimental visit, prior to exercise, body mass was measured using digital scales 162 (Seca 700; Seca Hamburg, Germany) to the nearest $0.1 \mathrm{~kg}$, and height was recorded to the 163 nearest $1 \mathrm{~cm}$ using a stadiometer (Harpenden Stadiometer, Holtain Limited, UK).

165 Capillary blood analysis

166 A 30- $\mu \mathrm{L}$ capillary blood sample was taken from the fingertip for analysis of BLa (YSI 2300, 167 Yellow Springs Instruments, Yellow Springs, $\mathrm{OH}$ ) following the completion of each 168 submaximal running speed. The LTP was identified via a derivation of the modified Dmax 169 method $^{24}$. Briefly, a fourth order polynomial curve was fitted to the speed-lactate relationship. 170 Lactate threshold (LT) was identified as the final stage preceding an increase in BLa $>0.4$ $171 \mathrm{mmol} \cdot \mathrm{L}^{-1}$ above baseline and a straight line was drawn between LT and the last 4-min stage 172 of running (i.e., an increase $>2 \mathrm{mmol} \cdot \mathrm{L}^{-1}$ or exceeding $4 \mathrm{mmol} \cdot \mathrm{L}^{-1}$ ). Finally, LTP was defined 
173 as the greatest perpendicular distance between this straight line and the fourth order

174 polynomial, to the nearest $0.5 \mathrm{~km} \cdot \mathrm{h}^{-1}$.

176 Pulmonary gas exchange

177 Breath-by-breath pulmonary gas exchange data were measured continuously throughout the 178 submaximal-, and maximal- protocols. Subjects wore a low-dead space mask and breathed 179 through an impeller turbine assembly (Jaeger Triple V, Jaeger GmbH, Hoechberg, Germany).

180 The inspired and expired gas volume and concentration signals were continuously sampled, 181 the latter using paramagnetic $\left(\mathrm{O}_{2}\right)$ and infrared $\left(\mathrm{CO}_{2}\right)$ analysers (Jaeger Vyntus CPX, 182 Carefusion, San Diego, CA) via a capillary line. These analysers were calibrated before each 183 test using a known gas mixture $\left(16 \% \mathrm{O}_{2}\right.$ and $\left.5 \% \mathrm{CO}_{2}\right)$ and ambient air. The turbine volume 184 transducer was calibrated using a 3-L syringe (Hans Rudolph, KS). The volume and 185 concentration signals were time aligned, accounting for the transit delay in capillary gas and 186 analyser rise time relative to the volume signal. Breath-by-breath $\mathrm{V}_{2}$ data were initially 187 examined to exclude errant breaths caused by coughing, swallowing etc., and those values 188 lying more than 4 SD from the local mean were removed. Subsequently, the breath-by-breath data were converted to second-by-second data using linear interpolation. $\dot{\mathrm{V}} \mathrm{O}_{2}, \dot{\mathrm{V}} \mathrm{CO}_{2}, \dot{\mathrm{V}}_{\mathrm{E}}$ and 190 RER were quantified for the final 60-s of each stage of the submaximal protocol. $\dot{\mathrm{VO}}_{2} \max$ 191 was determined as the highest 30-s moving average.

Calculation of the energy cost of running

194 The 60-s average $\dot{\mathrm{VO}}_{2}$ and $\dot{\mathrm{V}} \mathrm{CO}_{2}$ data collected during the final minute of each submaximal 195 stage were used to calculate the energy cost of running. Updated non-protein respiratory 196 quotient equations ${ }^{25}$ were used to estimate substrate utilisation (g.min ${ }^{-1}$ ). The energy derived 197 from each substrate was calculated by multiplying fat and carbohydrate utilisation by 9.75 
$198 \mathrm{kcal}$ and $4.07 \mathrm{kcal}$, respectively. ${ }^{26}$ Absolute energy cost was calculated as the sum of the energy derived from fat and carbohydrate for each submaximal running speed SLTP, and with an RER value of $<1.00$, in order to ensure an insignificant anaerobic contribution to

201 energy expenditure. Running economy was expressed in $\left(\mathrm{kcal} \cdot \mathrm{kg}^{-1} \cdot \mathrm{km}^{-1}\right)$.

202

203

\section{Data Analysis}

204 Each participant's energy cost-running speed relationship was fitted with a $3^{\text {rd }}$ order 205 polynomial function for all speeds $<$ sLTP in order to interpolate their energy cost at relative 206 submaximal speeds, which was assessed in 5\% increments from 50\% and 70\% sLTP for the 207 elite and recreational groups, respectively. In all cases the $3^{\text {rd }}$ order polynomial function 208 provided a good fit to the experimental data $\left(R^{2}=0.948 \pm 0.060\right)$.

210 To verify the use of linear ratio scaling of energy cost measurements (i.e., $\mathrm{kg}^{-1}$ ) in the current 211 population, as indicated by our previous work, ${ }^{8}$ plots of body mass against energy cost were 212 fitted with both power and linear ratio functions. The power function revealed exponents 213 close to unity (males, 0.96; females, 1.13), indicating that a linear ratio, which involves an 214 exponent of 1.00, is appropriate. Furthermore, the linear ratio and power functions produced 215 similar $R^{2}$ values (Males: [Linear; 0.56 vs. Power; 0.57], Females: [Linear; 0.72 vs. Power; 216 0.73]), and root mean square error (Males: [Linear; 5.41 vs. Power; 5.43], Females: [Linear; 2174.43 vs. Power; 4.42]) values. The appropriateness of the linear ratio scaling was also 218 confirmed by the absence of any relationship between body mass and energy cost per kg 219 (linear ratio scaled) for males (both; $\mathrm{r}=-0.033, P=0.821$ ) and females (both; linear; $\mathrm{r}=0.171$, $220 P=0.244)$. Consequently, relative expressions of energy cost were linear ratio scaled to $\mathrm{BM}^{-1}$ 221 in all further analyses. 


\section{Statistical Analysis}

224 An independent samples one-way ANOVA was used to investigate anthropometric and 225 physiological differences between groups. A one-way ANOVA was used to investigate 226 differences in energy cost according to sex (males vs. females). The influence of speed 227 (absolute: [8-12 km.h ${ }^{-1}$ for recreational; 8-17 $\mathrm{km} \cdot \mathrm{h}^{-1}$ for high-level] and relative: [70-95\% 228 sLTP for recreational; 50-95\% sLTP for high-level] on energy cost was investigated using 229 one-way ANOVAs with repeated measures (RM). A two-way RM ANOVA (speed x 230 performance standard) was used to consider differences in energy cost according to 231 performance standard (high-levele vs. recreational). Post hoc analysis with Bonferonni 232 adjustment was used to identify the origin of any significant difference. An independent 233 samples $t$-test was used to determine whether the most economical running speed was 234 different between the elite and recreational groups. All data are presented as mean \pm SD. 235 Statistical analysis was performed using SPSS version 22 (SPSS Inc., Chicago, Illinois, USA) 236 with significance set as $P<0.05$.

\section{RESULTS}

239 Male and female runners classified as either high-level or recreational were of similar

240 running standards, indicated by similar proximities to the sex-specific 10 -km road world

241 record time (Table 1). Males had a greater $\dot{\mathrm{VO}}_{2} \max$, sLTP, height, body mass, and body mass 242 index (BMI) relative to females (Table 1). The performance standard of the high-level males 243 and females in comparison to the recreational groups was emphasised by their percentage of 244 10-km road world record times, as well as their higher $\mathrm{V}_{2}$ max and sLTP values. 
247 There were no sex differences in the energy cost of running for the recreational runners at 248 8-12 $\mathrm{km} \cdot \mathrm{h}^{-1}(P=0.289$; Figure $1 \mathrm{~A})$, or high-level runners at 8-17 $\mathrm{km} \cdot \mathrm{h}^{-1}(P=0.766$; Figure $1 \mathrm{~B})$.

249 Similarly, no differences were observed between males and females within either group 250 (i.e., recreational and high-level) when the energy cost of running was compared at relative 251 speeds (Recreational, 70-95\% sLTP; Elite, 50-95\% sLTP) (Figure 1C, 1D; $P=0.338 ; P=0.937$, respectively). Given the similarity between male and female data the two sex groups were considered together in subsequent analyses.

254

255

Speed and Energy Cost

256 There was a speed effect on the energy cost of running for the high-level and recreational 257 running groups (Figure 2). For the high-levelgroup, as absolute speed increased there was a 258 decrease in the energy cost of running for each $1 \mathrm{~km} \cdot \mathrm{h}^{-1}$ increment between $9 \mathrm{~km} \cdot \mathrm{h}^{-1}$ and 11 $259 \mathrm{~km} \cdot \mathrm{h}^{-1}$ (all $\left.P<0.001\right)$. A plateau was evident between 11 and $16 \mathrm{~km} \cdot \mathrm{h}^{-1}(P>0.05)$, and an 260 increase in energy cost was observed between 16 and $17 \mathrm{~km} \cdot \mathrm{h}^{-1}(P<0.01)$. The nadir of this 261 relationship, and thus the most economical running speed, occurred at $13 \mathrm{~km} \cdot \mathrm{h}^{-1}$, which was $14 \%$ more economical than running at $8 \mathrm{~km} \cdot \mathrm{h}^{-1}$ and $3 \%$ more economical than running at $26317 \mathrm{~km} \cdot \mathrm{h}^{-1}$. For the recreational group, the energy cost of running decreased with each increment in running speed $\left(8-12 \mathrm{~km} \cdot \mathrm{h}^{-1}\right.$; all $\left.\mathrm{P}<0.001\right)$.

266 Similar relationships were observed for both high-level and recreational runners when the 267 speed-energy cost relationship was considered for relative running speeds (i.e., \% sLTP). The 268 high-level group exhibited a decrease in energy cost $(50-70 \%$ sLTP; all $P<0.001)$ until the attainment of a plateau (70-80\% sLTP, $P>0.05$ ), and a subsequent increase in energy cost

270 (80-95\% sLTP; all $P<0.001)$. The nadir and most economical speed occurred at 70\% sLTP,

271 which was 9\% more economical than at 50\% sLTP. In the recreational group, the energy cost 
272 of running progressively decreased (70-85\% sLTP; $P<0.001)$, to attain a plateau (85-95\%

273 sLTP). The most economical running speed for the recreational group was $90 \%$ sLTP, a $4 \%$

274 improvement in running economy relative to running at 70\% sLTP. Expressed as a \% sLTP,

275 the most economical running speed was significantly greater for the recreational $(90 \pm 10 \%$

$276 \quad s L T P)$ relative to the high-level $(70 \pm 10 \% s L T P)$ group $(P<0.001)$.

277

278

Performance standard and Energy Cost

279 Significant differences in the energy cost of submaximal running were observed between the 280 high-level and recreational groups for both absolute and relative running speeds $(P<0.001$;

281 Figure 3). Comparing the absolute speeds common to all runners (i.e., 8-12 $\mathrm{km} \cdot \mathrm{h}^{-1}$; $n=92$ ) the 282 high-level group $\left(0.97 \pm 0.09 \mathrm{kcal} \cdot \mathrm{kg}^{-1} \cdot \mathrm{km}^{-1}\right)$ were $\sim 8 \%$ more economical than the 283 recreational group $\left(1.06 \pm 0.09 \mathrm{kcal} \cdot \mathrm{kg}^{-1} \cdot \mathrm{km}^{-1}\right)$. Similarly, the high-level group were more 284 economical (7-17\% lower) at all relative speeds (70\%-95\% sLTP) than the recreational group, although this difference was greatest at 70\% sLTP (17\%).

286

\section{DISCUSSION}

288 The current study assessed the energy cost of running in a large sample of runners, across a 289 wide range of absolute and relative speeds to determine the influence of sex, speed and 290 performance standard. The principle findings of this study were that: 1) there was no 291 sex-dependent difference in the energy cost of running at the same absolute or relative 292 (\% sLTP) running speeds for males and females of equivalent standard; 2) for high-level 293 runners there was a "u-shaped” relationship between absolute and relative running speed and 294 energy cost with the most economical speed being $13 \mathrm{~km} \cdot \mathrm{h}^{-1}$ (absolute) or $70 \% \mathrm{sLTP}$ 295 (relative), and; 3) high-level endurance runners had a lower energy cost, thus a better running 296 economy at each absolute and relative (\% sLTP) running speed. 
298 Speed

299 The results demonstrated that running economy is influenced by running speed, with high300 level runners examined across a wide-range of running speeds (8-17 $\left.\mathrm{km} \cdot \mathrm{h}^{-1} ; 50-95 \% \mathrm{sLTP}\right)$ 301 exhibiting "u-shaped" absolute and relative speed-energy cost relationships, with the most 302 economical running speed being $13 \mathrm{~km} \cdot \mathrm{h}^{-1}$ or $70 \%$ sLTP. In contrast, for the recreational 303 group energy cost decreased with speed until the highest common speed that valid energy 304 cost measurements ( $<$ LTP and RER <1.00) could be obtained for all of these participants, 305 which restricted these measurements to a much smaller range of speeds than the elite group $306\left(8-12 \mathrm{~km} \cdot \mathrm{h}^{-1} ; 70-95 \% \mathrm{sLTP}\right)$. The curvilinear energy cost-speed relationship observed for the 307 high-level group is consistent with some preliminary reports $(n=9) ;{ }^{10,11}$ that also considered 308 measurements over a wide range of speeds, and whilst a number of other studies have 309 typically reported linear or no speed-energy cost relationships this appears attributable to a 310 much more limited range of speeds.$^{6-8}$ For example, when comparing across a similar range 311 of speeds to our previous work, the last 4 speeds before $s \mathrm{LTP},{ }^{8}$ we also observed a greater 312 energy cost for running, thus poorer running economy, as speed increased (Figure 2C). An 313 optimal movement speed for walking has long been documented, ${ }^{27}$ and the current study 314 provides convincing evidence that this is also the case for running. Although there was only a small ( 4\%) difference between the most economical running speed and 95\% sLTP, these findings may be practically meaningful to an ultra-marathon competitor for instance, since a

$31765 \mathrm{~kg}$ male has been shown to expend $\sim 6000 \mathrm{kcal}$ per day during a 2-wk event. ${ }^{28}$

319 Interestingly, when considered relative to the sLTP, the most economical running speed for 320 the recreational cohort (90\% sLTP) was greater than that for the high-level cohort $(70 \%$ 321 sLTP). This difference might suggest an absolute biomechanical speed-effect limiting the 
322 most economical speed in the high-level group to a relatively low speed $\left(70 \% \mathrm{sLTP}, 13 \mathrm{~km} \cdot \mathrm{h}^{-}\right.$

$32{ }^{1}$ ) despite their physiological capacity to run at faster speeds (sLTP $\geq 17 \mathrm{~km} \cdot \mathrm{h}^{-1}$ ). Furthermore,

324 the most economical running speeds reported in the present study are similar to those

325 reported by Steudel-Numbers and Wall-Scheffler ${ }^{11}$ and Willcockson et al. ${ }^{10}\left(\sim 3.5\right.$ m.s ${ }^{-1}, 12.6$

$326 \mathrm{~km} \cdot \mathrm{h}^{-1}$ ). Further research is necessary to understand the factors that regulate the most

327 economical running speed, and the trainability of this speed.

328

329 Sex

330 The findings of this study demonstrated that there was no sex-specific difference in running 331 economy, measured as energy cost per unit mass and distance $\left(\mathrm{kcal} \cdot \mathrm{kg}^{-1} \cdot \mathrm{km}^{-1}\right)$, for males and 332 females of equivalent performance standard. These findings are in agreement with some ${ }^{7,16}$, 333 but not other previous studies. ${ }^{12-15}$ The differences between studies may be explained by 334 several methodological limitations, including: the assessment of oxygen cost to determine 335 running economy, ${ }^{12-16}$ which may be confounded by differences in substrate utilisation ${ }^{6,8}$; and 336 lack of control for performance standard. ${ }^{12-16}$ The present study accounted for these potential 337 confounders by determining the energy cost of running, and comparing male and female 338 runners of equivalent high-level and recreational performance standards.

\section{$340 \quad$ Performance standard}

341 Despite differences in its assessment, running economy has consistently been shown to be

342 influenced by performance standard, with runners of a better performance standard being 343 more economical. ${ }^{17,18}$ The findings of the current study support those of earlier research and 344 demonstrate that a high-level group of runners were more economical at each absolute ( 9\%) 345 and at each relative ( $7 \%$ to $13 \%$ ) running speed compared to the recreational group (Figure 3). This difference could be due to both innate characteristics (e.g., calcaneus length; ${ }^{29}$ 
347 muscle-tendon morphology ${ }^{30}$ ) and differences in training. For example, running regularly

348 for $>6$ months has been shown to improve running economy ${ }^{31}$, which may be related to 349 preferential changes in running technique, ${ }^{32}$ muscle energetics ${ }^{33}$ and/or body composition. ${ }^{34}$

350

351 Limitations

352 It is important to acknowledge the presence of an additional slowly developing component to 353 the $\mathrm{O}_{2}$ cost, termed the $\dot{\mathrm{V}} \mathrm{O}_{2}$ slow component, at all speeds above the lactate threshold. ${ }^{35}$ Due 354 to the large number of stages within the current protocol each stage was of a relatively short 355 duration (4 min), whereas, the full manifestation of the $\dot{\mathrm{VO}}_{2}$ slow component and thus 356 attainment of a true submaximal steady-state may take up to $20 \mathrm{~min}^{35}$. Thus the current study 357 was unable to fully account for the influence of the $\dot{\mathrm{VO}}_{2}$ slow component on the energy-cost 358 speed relationship. However, as the amplitude of the $\dot{\mathrm{VO}}_{2}$ slow component is known to be greater at higher speeds/intensities between the LT and LTP (i.e., heavy intensity domain ${ }^{36}$ ) it is likely that the current protocol underestimated the energy cost at higher speeds, in which 361 case the ascending limb of the speed-Ec relationship (13-17 $\mathrm{km} \cdot \mathrm{h}^{-1}$ in the high-level runners) may rise more steeply than we have documented. Future research could use a reduced number of stages of longer duration, or repeated test sessions, in order to more fully investigate the ascending limb of the speed-Ec relationship. We also recognise that substrate metabolism and thus potentially energy cost may be influenced by other variables, for example: prior exercise ${ }^{37}$; nutrition ${ }^{38}$; and temperature ${ }^{39,40}$. Hence participants were instructed to attend the laboratory after $36 \mathrm{~h}$ without strenuous exercise, following their habitual nutrition, and ran in the laboratory in standardised conditions. 
371 The speed-energy cost relationship documented in the current study indicates that

372 measurements at different speeds are not comparable. Given that energy cost was sensitive to

373 differences in both absolute and relative speed it raises the question whether measurements

374 should be made at the same absolute or relative speed. This is likely to depend on the nature

375 of the question under investigation; however, in the majority of cases we would recommend

376 the use of the same absolute running speed so that the prescribed task is consistent for all 377 participants and pre/post interventions. Furthermore, future studies should be mindful that 378 male and female energy cost values are comparable, and could be considered 379 together/interchangeably but performance standard clearly influences energy cost, which 380 might suggest distinct consideration of this variable in some studies.

382 Conclusion

383 In conclusion, the findings of this study demonstrate that when running economy is expressed 384 as the energy cost of running, there is a "u-shaped" relationship with speed; there is no 385 sex-specific difference; and, high-level endurance runners exhibit a better running economy 386 than recreational endurance runners. Due to the influence of speed on energy cost it is 387 recommended that future investigations primarily compare energy cost measurements at the same absolute running speed. Identification of the most economical running speed may be of importance to ultra-endurance athletes, and factors governing this speed and its trainability 390 warrant further investigation. 


\section{References}

1. Foster C, Lucia A. Running economy: the forgotten factor in elite performance. Sports Med. 2007; 37: 316-319.

2. Saunders PU, Pyne DB, Telford RD, Hawley JA. Factors affecting running economy 401 in trained distance runners. Sports Med. 2004; 34: 465-485.

402

3. Bassett DR, Howley ET. Limiting factors for maximum oxygen uptake and 403 determinants of endurance performance. Med Sci Sports Exerc. 2000; 32: 70-84.

404

4. Lucia A, Esteve-Lanao J, Olivan J, Gomez-Gallego F, San Juan AF, Santiago C, 405 Perez M, Chamorro-Vina C, Foster C. Physiological characteristics of the best Eritrean runners - exceptional running economy. Appl Phys Nutr Metab. 2006; 31:

407 530-540.

408

5. Lacour JR, Bourdin M. Factors affecting the energy cost of level running at submaximal speed. Eur J Appl Physiol. 2015; 115: 651-673.

6. Fletcher JR, Esau SP, Macintosh BR. Economy of running: beyond the measurement of oxygen uptake. J Appl Physiol. 2009; 107: 1918-1922.

7. Fletcher JR, Pfister TR, MacIntosh BR. Energy cost of running and Achilles tendon stiffness in man and woman trained runners. Physiol Rep. 2013; 1: e00178.

8. Shaw AJ, Ingham SA, Folland JP. The valid measurement of running economy in runners. Med Sci Sports Exerc. 2014; 46: 1968-1973.

9. Iaia FM, Hellsten Y, Nielsen JJ, Fernstrom M, Sahlin K, Bangsbo J. Four weeks of speed endurance training reduces energy expenditure during exercise and maintains muscle oxidative capacity despite a reduction in training volume. J Appl Physiol. 2009; 106: 73-80. 
10. Willcockson MA, Wall-Scheffler CM. Reconsidering the effects of respiratory constraints on the optimal running speed. Med Sci Sports Exerc. 2012: 44; 1344-1350.

11. Steudel-Numbers KL, Wall-Scheffler CM. Optimal running speed and the evolution of hominin hunting strategies. J Hum Evol. 2009: 56; 355-360.

12. Daniels J, Daniels N. Running economy of elite male and female runners. Med Sci Sports Exerc. 1992; 24: 483-489.

13. Howley ET, Glover ME. The caloric costs of running and walking one mile for men and women. Med Sci Sports. 1974; 6: 235-237.

14. Helgerud J. Maximal oxygen uptake, anaerobic threshold and running economy in women and men with similar performances level in marathons. Eur J Appl Physiol. 1994; 68: 155-161.

15. Helgerud J, Oyvind S, Hoff J. Are there differences in running economy at different velocities for well-trained distance runners? Eur J Appl Physiol. 2010; 108: 10991105.

16. Ingham SA, Whyte GP, Pedlar C, Bailey DM, Dunman N, Nevill AM. Determinants of 800-m and 1500-m running performance using allometric models. Med Sci Sports Exerc. 2008; 40: 345-350.

17. Morgan DW, Bransford DR, Costill DL, Daniels JT, Howley ET, Krahenhuhl GS. Variation in the aerobic demand of running among trained and untrained subjects. Med Sci Sports Exerc. 1995; 27: 404-409.

18. Pollock ML. Submaximal and maximal working capacity of elite distance runners. Part I: Cardiorespiratory Aspects. Ann NY Acad Sci. 1977; 301: 310-322. Hamadeh MJ. Influence of endurance exercise training and sex on intramyocellular 
lipid and mitochondrial ultrastructure, substrate use, and mitochondrial enzyme activity. Am J Physiol Regul Integr Comp Physiol. 2007; 292: R1271-R1278.

21. Romijn J, Coyle E, Sidossis L, Gastaldelli A, Horowitz J, Endert E, Wolfe R. Regulation of endogenous fat and carbohydrate metabolism in relation to exercise intensity and duration. Am J Physiol. 1993; 265: 380-391.

22. Febbraio MA, Carey MF, Snow RJ, Stathis CG, Hargreaves M. Influence of elevated muscle temperature on metabolism during intense, dynamic exercise. Am J Physiol Regul Integr Comp Physiol. 1996; 271: R1251-R1255.

23. International Association of Athletics Federations. (2014) Website [Internet]. IAAF Scoring tables of athletics-outdoors. Accessed 2015 January 5: http://www.iaaf.org/about-iaaf/documents/technical

24. Bishop D, Jenkins DG, Mackinnon LT. The relationship between plasma lactate parameters, Wpeak and 1-h cycling performance in women. Med Sci Sports Exerc, 1998; 30: 1270-1275.

25. Peronnet F, Massicotte D. Table of non-protein respiratory quotient: an update. Can $J$ Sport Sci. 1991; 16: 23-29.

26. Jeukendrup AE, Wallis GA. Measurement of substrate oxidation during exercise by means of gas exchange measurements. Int J Sports Med. 2005; 26: S28-S37.

27. Ralston HJ. Energy-speed relation and optimal speed during level walking. Int $Z$ agnew Physiol. 1958; 17: 277-283.

28. Hill RJ, Davies PS. Energy expenditure during 2 wk of an ultra-endurance run around Australia. Med Sci Sports Exerc. 2001; 33: 148-151.

29. Raichlen DA, Armstrong H, Lieberman DE. Calcaneus length determines running economy: implications for endurance running performance in modern humans and Neandartals. J Hum Evol. 2011; 60: 299-308. 
30. Arampatzis A, De Monte G, Karamanidis K, Morey-Klapsing G, Stafilidis S, Bruggemann GP. Influence of the muscle-tendon unit's mechanical and morphological properties on running economy. J Exp Biol. 2006; 209: 3345-3357.

31. Patton JF, Vogel JA. Cross-sectional and longitudinal evaluations of an endurance training programme. Med Sci Sports Exerc. 1977; 9: 100-103.

32. Boyer KA, Silvernail JF, Hamill J. The role of running mileage on coordination patterns in running. J Appl Biomech. 2014; 30: 649-654.

33. Baur H, Hirshmuller A, Muller S, Cassel M, Mayer F. Is EMG of the lower leg dependent on weekly running mileage? Int J Sports Med. 2012; 33: 53-57.

34. Ghiani G, Marongiu E, Melis F, Angioni G, Sanna I, Loi A, Pusceddu M, Pinna V, 480 Crisafulli A, Tocco F. Body composition changes affect energy cost of running during 12 months of specific diet and training in amateur athletes. Appl Physiol Nutr Metab. 2015; 40: 938-944.

35. Burnley M, Jones AM. Oxygen uptake kinetics as a determinant of sports performance. Eur J Sport Sci. 2007; 7: 63-79.

36. Carter H, Jones AM, Barstow TJ, Burnley M, Williams CA, Doust JH. Oxygen 486 uptake kinetics in treadmill running and cycle ergometry: a comparison. J Appl Physiol. 2000; 89: 899-907.

37. Goto K, Ishii N, Mizuno A, Takamatsu K. Enhancement of fat metabolism by 489 repeated bouts of moderate endurance exercise. J Appl Physiol. 2007; 102: 2158-2164.

38. Achten J, Jeukendup AE. Optimising fat oxidation through exercise and diet. Nutrition. 2004; 20: 716-727.

39. Febbraio MA, Snow RJ, Stathis CG, Hargreaves M, Carey MF. Effect of heat stress on muscle energy metabolism during exercise. J Appl Physiol. 1994; 77: 2827-2831. 
40. Parkin JM, Carey MF, Zhao S, Febbraio MA. Effect of ambient temperature on human skeletal muscle metabolism during fatiguing submaximal exercise. JAppl Physiol. 1999; 86: 902-908.

497

498

499

500

501

\section{Figure Legends}

503 Figure 1 The effect of sex on running economy. Males (white circles) and females (black 504 circles) are shown at the same absolute (panels A and B) and relative (panels C and D) speeds 505 for the recreational (panels A and C) and high-level (panels B and D) groups. At absolute 506 speeds (i.e., panels A and B) positive error bars are displayed for the male group, and 507 negative error bars are displayed for female group. At relative speeds (i.e., panels C and D) 508 positive error bars are displayed for the female group and negative error bars are displayed 509 for the male group.

510

511 Figure 2 The effect of speed on running economy for the recreational (panels A and C) and 512 high-level (panels B and D, n=24) runners at the same absolute (panels A and B, n=68) and 513 relative (panels C and D) speeds. *Statistically significant differences between speeds $514(P<0.05)$.

515

516 Figure 3 The effect of performance standard on running economy at the same absolute (panel 517 A) and relative (panels B) speeds for the high-level (solid line, black circle markers, $\mathrm{n}=24$ ) 
518 and recreational (solid line, white circle markers, $n=68$ ) groups. *Statistically significant

519 between group difference $(P<0.05)$.

520

521

522

523

524

525

526 
527 Table 1 Physiological and anthropometrical characteristics for elite and recreational runners.

\begin{tabular}{|c|c|c|c|c|c|c|c|c|c|c|}
\hline & & $n$ & $\begin{array}{c}\text { Age } \\
(y)\end{array}$ & $\begin{array}{l}\text { Height } \\
\text { (m) }\end{array}$ & $\begin{array}{c}\text { Body Mass } \\
\text { (kg) }\end{array}$ & $\begin{array}{c}\text { BMI } \\
\left(\mathrm{kg} \cdot \mathrm{m}^{-2}\right)\end{array}$ & $\begin{array}{c}s \mathbf{S L P} \\
\left(\mathbf{k m} \cdot \mathrm{h}^{-1}\right)\end{array}$ & $\begin{array}{c}\dot{\mathrm{V}} \mathrm{O}_{2} \max \\
\left(\mathrm{ml} \cdot \mathrm{kg} \cdot \mathrm{min}^{-1}\right)\end{array}$ & $\begin{array}{l}\text { \% } 10 \text { km Road } \\
\text { World Record }\end{array}$ & $\begin{array}{l}\text { Training mileage } \\
\left(\text { miles.wk }^{-1}\right)\end{array}$ \\
\hline \multirow{3}{*}{ High-level } & Male & 14 & $27 \pm 7$ & $1.80 \pm 0.06^{\#}$ & $67.3 \pm 6.8^{\#}$ & $20.8 \pm 1.4^{* \#}$ & $19.0 \pm 1.0^{* \#}$ & $69.5 \pm 5.4^{* \#}$ & $113 \pm 2^{*}$ & $70 \pm 20^{* \#}$ \\
\hline & Female & 10 & $25 \pm 4$ & $1.67 \pm 0.06^{\#}$ & $52.1 \pm 5.2^{* \#}$ & $18.6 \pm 1.0^{* \#}$ & $18.0 \pm 1.0^{* \#}$ & $63.8 \pm 4.5^{* \#}$ & $113 \pm 3^{*}$ & $52 \pm 9^{* \#}$ \\
\hline & Total & 24 & $26 \pm 6$ & $1.75 \pm 0.09$ & $61.0 \pm 9.8^{*}$ & $19.9 \pm 1.7^{*}$ & $19.0 \pm 1.0^{*}$ & $67.1 \pm 5.7^{*}$ & $113 \pm 2^{*}$ & $63 \pm 19^{*}$ \\
\hline \multirow{3}{*}{ Recreational } & Male & 35 & $30 \pm 7$ & $1.78 \pm 0.07^{\#}$ & $69.5 \pm 6.3^{\#}$ & $21.9 \pm 1.4^{* \#}$ & $16.0 \pm 2.0^{* \#}$ & $59.1 \pm 5.3^{* \#}$ & $157 \pm 17^{*}$ & $32 \pm 17^{* \#}$ \\
\hline & Female & 33 & $29 \pm 7$ & $1.65 \pm 0.08^{\#}$ & $57.1 \pm 6.5^{* \#}$ & $20.9 \pm 1.6^{* \#}$ & $14.0 \pm 1.0^{* \#}$ & $52.1 \pm 4.2^{* \#}$ & $158 \pm 13^{*}$ & $23 \pm 12^{* \#}$ \\
\hline & Total & 68 & $29 \pm 7$ & $1.73 \pm 0.09$ & $63.5 \pm 8.9^{*}$ & $21.4 \pm 1.5^{*}$ & $15.0 \pm 2.0^{*}$ & $55.7 \pm 6.0^{*}$ & $157 \pm 15^{*}$ & $28 \pm 15^{*}$ \\
\hline
\end{tabular}

528 Post hoc differences $(P<0.05)$ for performance standard are denoted * and within group differences for sex are denoted by ${ }^{\sharp}$ 

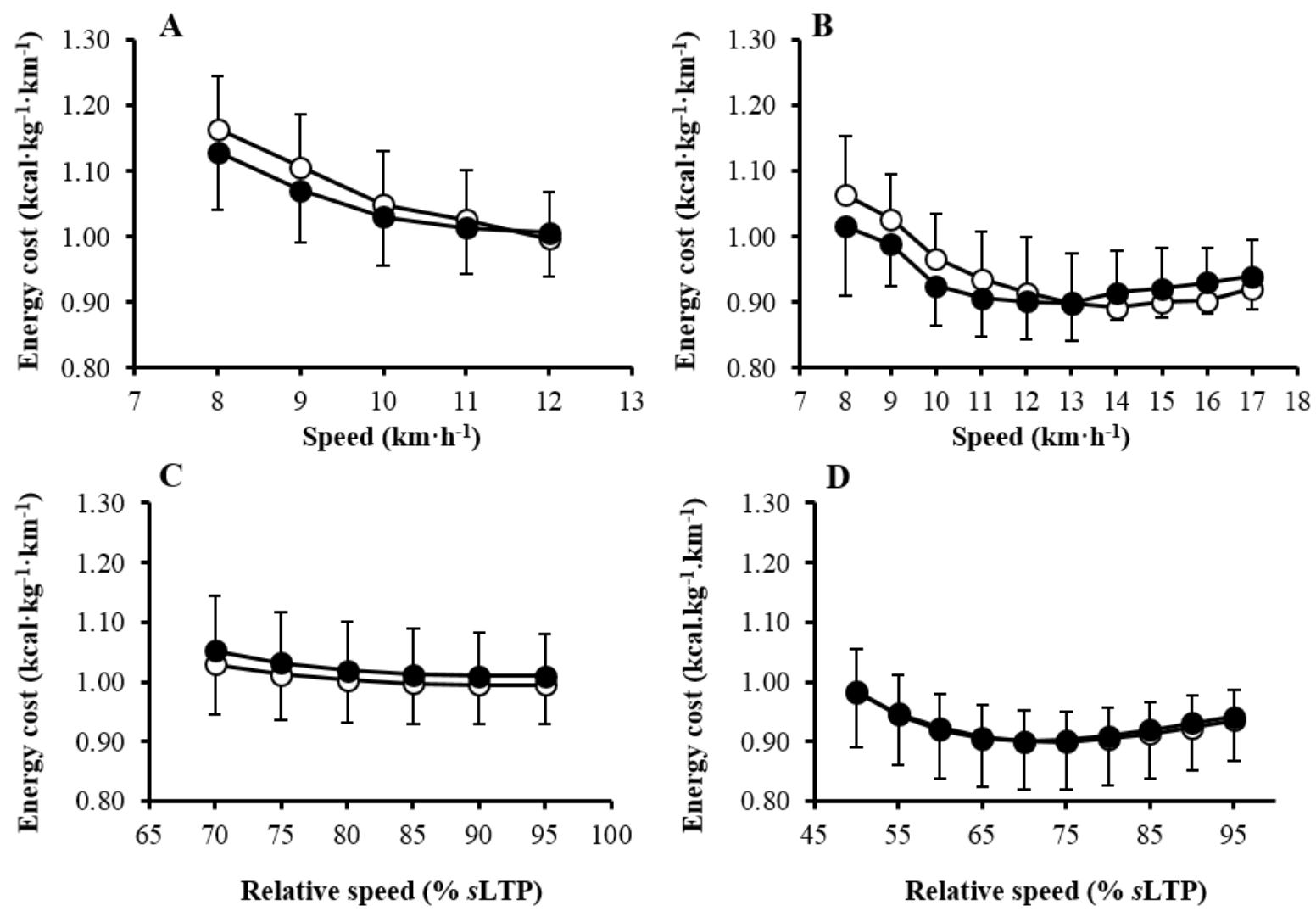

\section{$538 \quad$ Figure 1}

539

540

541

542

543

544

545

546

547

548

549 

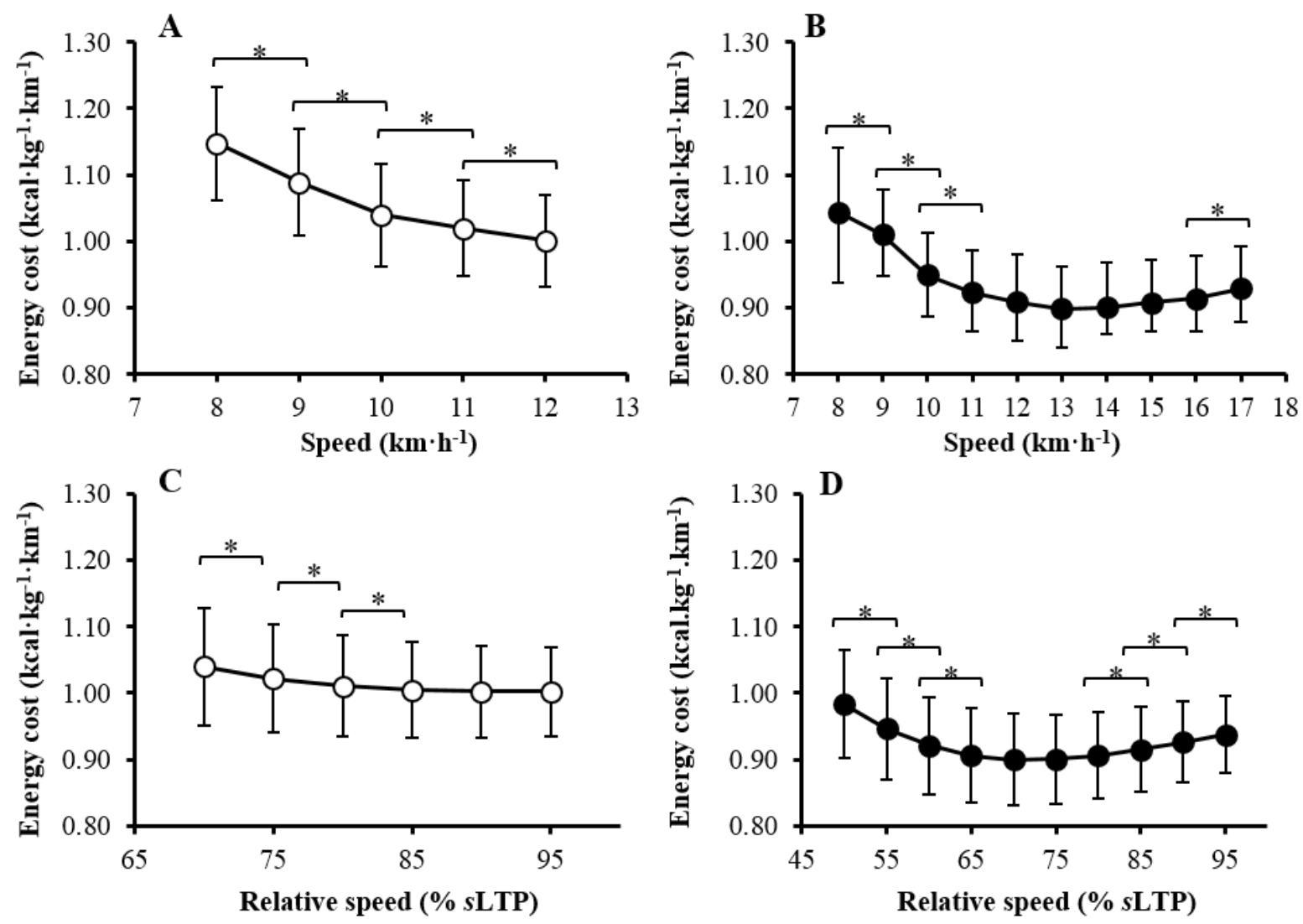

551

\section{Figure 2}

553

554

555

556

557

558

559

560

561

562

563

564 

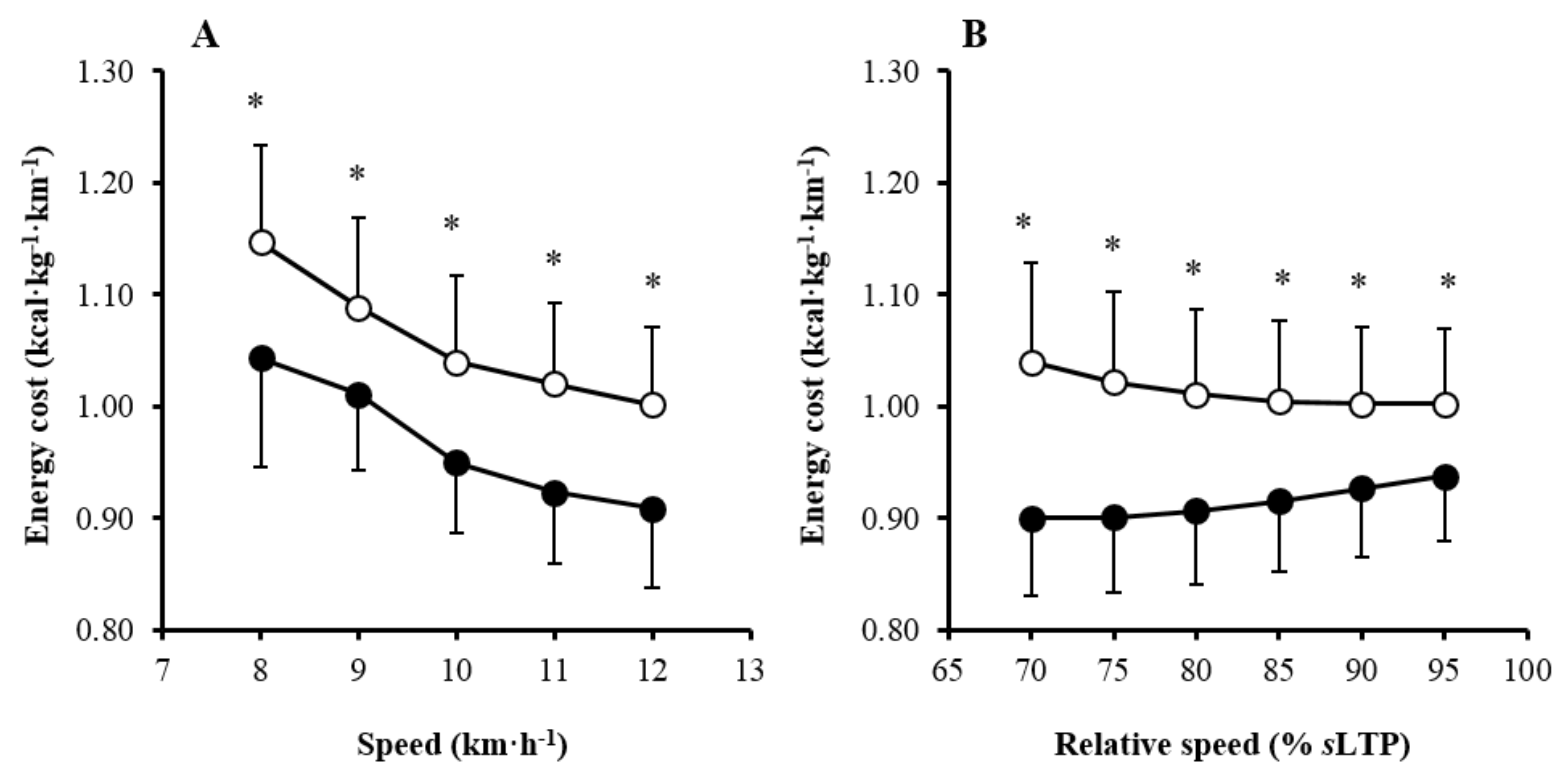

565

$566 \quad$ Figure 3 